\title{
Evaluation of Emotional and Behavioral Problems in School-Age Children of Patients with Breast Cancer
}

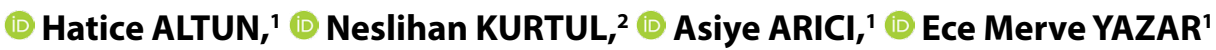 \\ 'Department of Child and Adolescent Psychiatry, Faculty of Medicine, Kahramanmaraş Sütçü İmam University, Kahramanmaraş-Turkey \\ ${ }^{2}$ Department of Radiation Oncology, Faculty of Medicine, Kahramanmaraş Sütçü İmam University, Kahramanmaraş-Turkey
}

\begin{abstract}
OBJECTIVE
The aim of the present study was to determine the emotional and behavioral problems among schoolage children of mothers with breast cancer $(\mathrm{BC})$ and the difficulties they experienced during the mothers' illness.

\section{METHODS}

The participants included 40 children and adolescents of patients with BC and age- and sex-matched 40 healthy controls between the ages of 6 and 17 years. The study group filled out a sociodemographic data form that was prepared by the researchers and evaluated the demographic data and psychosocial effects of maternal cancer on children. The parents of all participants filled out the Strengths and Difficulties Questionnaire (SDQ), Parent Form to determine the emotional and behavioral problems in children.

\section{RESULTS}

Conduct problems, attention deficit and hyperactivity, and total difficulty scores of the SDQ were significantly higher in children of mothers with $\mathrm{BC}(\mathrm{p}<0.05)$. Scores for emotional problems, peer relationship problems, and prosocial behaviors were similar in both groups. Scores for emotional problems, peer problems, and total difficulties were significantly higher in girls of patients with $\mathrm{BC}$ than in boys. There was positive correlation between child's age and total difficulty scores $(p<0.05)$. There were several problems, such as changes in new family responsibilities and some life difficulties, in children and adolescents of patients with BC.
\end{abstract}

\section{CONCLUSION}

The results of the present study showed that the emotional and behavioral problems of children and adolescents of mothers with $\mathrm{BC}$ were higher than those of controls, and that maternal illness caused distress for children in many areas of their lives. Our results may increase the awareness of health care providers that some children may have difficulties in adjusting to their parents' illness.

Keywords: Adolescent; breast cancer; children; emotional and behavioral problems; life difficulties. Copyright $\odot$ 2019, Turkish Society for Radiation Oncology

\section{Introduction}

Breast cancer (BC) is the most common type of cancer in women. In 2018, approximately 266,120 new BC cases and 40,920 BC deaths were expected to occur in women, and female BC represents $15.3 \%$ of all new cancer cases in the United States.[1,2] In addition, the proportion of women who were diagnosed with $\mathrm{BC}$ before the age of 40 years has increased, corresponding to $6.6 \%$ of the total number of cases diagnosed with
Received: July 21, 2018

Accepted: December 11, 2018

Online: February 28, 2019

Accessible online at:

www.onkder.org
Dr. Hatice ALTUN

Kahramanmaraş Sütçü İmam Üniversitesi,

Tıp Fakültesi,

Çocuk ve Ergen Psikiyatrisi Anabilim Dalı,

Kahramanmaraş-Turkey

E-mail: drhaticealtun@gmail.com 
BC.[3] An increase in the number of individuals diagnosed with cancer and the prolongation of patient survival in parallel with improvements in diagnostic and treatment modalities lead to more active participation of family members of patients with cancer in the care process and/or getting greater responsibility for the care of patients.[4-6] Having a life-threatening illness may lead to the development of emotional problems in parents or decrease their coping skills by increasing stress that may decrease attention to their children. [710] It is reported that both maternal depression and impaired parenting skills had negative effects on family and child functioning in families affected by cancer. Limited communication and scarcity of sharing in the family also negatively affect functionality. [11-13]

A BC diagnosis not only affects the patient but also causes a crisis in the family system, causing changes in family dynamics, roles, rules, and routines. A particular challenge for $\mathrm{BC}$-diagnosed mothers $<40$ years is that their children are younger and more dependent on the mother.[10,14-16] Previous studies have reported higher rates of psychological distress, such as anxiety and depression, in patients with cancer with $<18$-yearold children and in their spouses. [8]

Encountering with parental cancer is very traumatizing for children, and many psychiatric disturbances, such as anxiety; depression; social withdrawal; emotional and behavioral problems; somatic complaints; and sad, angry, and aggressive behaviors, can be seen in children during this period depending on their age and gender.[17-23] In addition, silencing, trying to get away from cancer, controlling the movements of the sick parent, and increased number of complaints with siblings and friends are seen in school-age children.[20] Parents' despair, depression, and situations in which the prognosis of the disease worsens are much more difficult for young people and school-age children.[22] However, there are mixed results in previous studies that compare children and adolescents who have a parent with cancer and control groups or national norms. $[20,23,24]$ Latency-age children were shown to have emotional and behavioral similarities with other children. $[25,26]$ However, some previous studies showed that adolescent-age children of patients with cancer had more emotional problems than other adolescents.[18,21,27] Other previous studies reported that these children and adolescents had functionality similar to or better than other children. [25,28,29]

It has been reported that children and adolescents of parents with cancer have psychological problems as well as alterations in their roles in the family, increased responsibilities, a decrease in social activities, and a loss of childhood as peer groups are needed for social development.[16,30,31]

Despite many studies have investigated the psychosocial aspects of cancer on patients with $\mathrm{BC}$ and their primary caregivers, data obtained for children and adolescents $<18$ years are not sufficient and have mixed results.[6,32-35] Especially in Turkey, there is a need for studies evaluating school-age children and adolescents. The aim of the present study was to determine the emotional and behavioral problems among school-age children of mothers with $\mathrm{BC}$ and the difficulties they experienced during the mothers' illness.

\section{Materials and Methods}

This was a cross-sectional case-control study. Children of patients with BC with an Eastern Cooperative Oncology Group performance status of $0-2$, who had a child aged 6-17 years, and who applied to receive adjuvant radiotherapy from Kahramanmaras Sutcu Imam University, Medical Faculty Hospital, Radiation Oncology Department were included. A total of 80 individuals (40 in the study group and 40 in the control group) were included in the study. For the study, patients with $\mathrm{BC}$ who were being treated in the radiation oncology department were called by phone, information about the study was provided, and questionnaire forms were given to the families who accepted to participate in the study to be filled out by the patient, the healthy parent, or their children at the childhood or adolescent age. Children with a known intellectual disability; autism spectrum disorder; substance abuse; psychosis and bipolar affective disorder; any neurological, genetic, metabolic, or endocrine disease; parents who are illiterate; and subjects who filled out questionnaire forms incompletely were excluded from the study. The study group filled out a sociodemographic data form that was prepared by the researchers and evaluated demographic data, mother's disease, and psychosocial problems that can be seen in children, and their parents filled out the Strengths and Difficulties Questionnaire (SDQ), Parent Form to determine the emotional and behavioral problems in children. The control group consisted of 40 age- and gender-matched healthy children who did not have any chronic, neurological, genetic, metabolic, endocrine, and psychiatric diseases or substance abuse and who had healthy parents. The control group was informed about the study and asked to fill in the 
scales used for the study. However, in the sociodemographic data form that was given to the control group, there were only questions with regard to demographic information, and there were no questions about the parents' sickness. The study was approved by the scientific research ethics committee of Sutcu Imam University, Medical Faculty, Kahramanmaras, Turkey. Written consent was obtained from all subjects who participated in the study.

\section{Measurements}

\section{Sociodemographic Data Form}

The sociodemographic data form was prepared by the researchers and included questions about age, gender, educational status, age of parents, role change within the family during the disease process, responsibilities, difficulties they experience, fear of getting ill, knowledge about the mother's disease, reaction to the disease, and thoughts about the seriousness of the disease.

\section{SDQ, Parent Form}

The SDQ was developed by Robert Goodman in 1997. The purpose of the SDQ is to investigate mental problems in children and young people. The SDQ includes 25 questions that investigate behavioral characteristics, some of which are positive and some are negative. These questions are subdivided into five subscales: "conduct problems," "attention deficit and hyperactivity," "emotional problems," "peer problems," and "prosocial behaviors." Each title is assessed within itself, and the sum of the first four subscales gives the total difficulty score. Although both the SDQ and the Child Behavior Checklist (CBCL) were developed for similar purposes, they have significant differences. The most important difference is their length. The second important difference is that because it has appropriate items that question the diagnostic criteria of the Diagnostic and Statistical Manual of Mental Disorders, $4^{\text {th }}$ Edition, especially for attention deficit and hyperactivity disorder, the SDQ can scan the problems in this area more meaningfully. Another difference is that in contrast to the CBCL, some items of the SDQ aim to question the positive areas and therefore allow the assessment of the strengths of the child and the adolescent. Evaluations with CBCL showed high-reliability values for both scales that were also correlated with each other. Turkish translation and validity and reliability study were performed by Guvenir et al.[36]

\section{Results}

The mean age of the cases in the study group was $13.37 \pm 2.94$ years, and the mean age of the healthy controls was $12.52 \pm 2.57$ years. There were no significant differences between the two groups with regard to mean age, age range, mean parental age, and gender $(\mathrm{p}>0.05)$ (Table 1). There was a statistically significant difference between the two groups with regard to emotional and behavioral problems $(\mathrm{p}<0.05)$. Conduct problems, attention deficit and hyperactivity, and total difficulty scores were significantly higher in children of mothers with $\mathrm{BC}(\mathrm{p} \leq 0.001$, $\mathrm{p}=0.001$, and $\mathrm{p}=0.002$, respectively). Scores for emotional problems, peer relationship problems, and prosocial behaviors were similar in both groups $(\mathrm{p}>0.05)$ (Table 2). With regard to gender, emotional problems, peer problems, and total difficulty scores were significantly higher in girls of patients with $\mathrm{BC}$ than in boys $(\mathrm{p}=0.024, \mathrm{p}=0.022$, and $\mathrm{p}=0.030$, respectively) (Table 3 ). Prosocial behavior score was lower, and emotional, conduct, and peer relationship problems; attention deficit and hyperactivity; and total difficulty scores were higher in 12-17-year-old adolescents than in 6-11-year-old children although the differences were not statistically significant $(p>0.05)$ (Table 4). Children whose mothers were diagnosed in the last year $(n=26,65 \%)$ had higher scores in emotional problems, conduct problems, attention deficit and hyperactivity, and total difficulty and lower scores in peer problems and prosocial behaviors than children whose mothers were diagnosed 1-5 years ago although the difference was not statistically significant ( $\mathrm{p}>0.05)$. Most children of mothers with $\mathrm{BC}$ experienced role changes in the family, they mostly undertook mother and caregiver roles, they had one or more responsibilities, and they had fears of becoming ill. Some variables, such as difficulties, responsibilities, and intrafamily role changes, according to gender and age range are given in Tables 3 and 4. According to the Spearman correlation analysis, there were statistically significant positive correlations between age of the case and total difficulty score $(\mathrm{r}=0.401, \mathrm{p}=0.010)$ and between maternal age and attention deficit and hyperactivity score in children of patients with $\mathrm{BC}(\mathrm{r}=0.357, \mathrm{p}=0.024)$.

\section{Discussion}

The present study evaluated emotional and behavioral problems, related factors, and life problems experienced by school-age children of mothers with BC and demonstrated that conduct problems, attention deficit and hyperactivity, and total difficulty scores were higher in school-age children and adolescents of mothers with BC than in children of healthy control parents; 
Table 1 Demographic and clinical data of children and adolescents of mothers with breast cancer (study group) and control groups

\begin{tabular}{|c|c|c|c|}
\hline & $\begin{array}{c}\text { Study } \\
\text { group } \\
(\text { Mean } \pm \text { SD)/n }(\%)\end{array}$ & $\begin{array}{c}\text { Controls } \\
\text { group } \\
(\text { Mean } \pm \text { SD }) / n(\%)\end{array}$ & $\mathbf{p}$ \\
\hline Age (years) & $13.37 \pm 2.94$ & $12.52 \pm 2.27$ & 0.173 \\
\hline Age range & & & 0.809 \\
\hline 6-11 age & $12(30 \%)$ & $13(32.5 \%)$ & \\
\hline $12-17$ age & $28(70 \%)$ & $27(67.5 \%)$ & \\
\hline Gender (female/male) & $25 / 15$ & $27 / 13$ & 0.639 \\
\hline Education (years) & $6.77 \pm 3.63$ & $6.50 \pm 3.06$ & 0.715 \\
\hline Maternal age & $43.70 \pm 5.25$ & $42.00 \pm 4.26$ & 0.116 \\
\hline Paternal age & $45.45 \pm 6.35$ & $45.85 \pm 4.09$ & 0.739 \\
\hline \multicolumn{4}{|l|}{ Awareness of the diagnosis $(n / \%)$} \\
\hline Yes & $29(72.5 \%)$ & & \\
\hline No & $11(27.5 \%)$ & & \\
\hline \multicolumn{4}{|l|}{ Diagnostic time } \\
\hline 6 month-1 year & $26(65 \%)$ & & \\
\hline $1-5$ years & $14(35 \%)$ & & \\
\hline \multicolumn{4}{|l|}{ Reaction to the disease } \\
\hline Yes (sorry, cry, anxiety ie) & $38(95 \%)$ & & \\
\hline No & $2(5 \%)$ & & \\
\hline \multicolumn{4}{|l|}{ Family roles } \\
\hline Changed (caregiver, mother) & $21(52.5 \%)$ & & \\
\hline Unchanged & $19(47.5 \%)$ & & \\
\hline \multicolumn{4}{|l|}{ New responsibilities } \\
\hline Being the mother's caregiver & $9(22.5 \%)$ & & \\
\hline Undertaking responsibilities of siblings & $11(27.5 \%)$ & & \\
\hline Do housework & $13(32.5 \%)$ & & \\
\hline Other & $8(20 \%)$ & & \\
\hline \multicolumn{4}{|l|}{ Experienced difficulties } \\
\hline Limitation of daily activities & $14(35 \%)$ & & \\
\hline Decrease in social activity with peer grups & $8(20 \%)$ & & \\
\hline Decrease in lesson work & $14(35 \%)$ & & \\
\hline Other & $9(22.5 \%)$ & & \\
\hline \multicolumn{4}{|l|}{ Fears of becoming ill } \\
\hline Yes & $22(55 \%)$ & & \\
\hline No & $18(45 \%)$ & & \\
\hline \multicolumn{4}{|l|}{ Perception of the severity of the mother's disease } \\
\hline Very serious & $20(50 \%)$ & & \\
\hline Serious & $16(40 \%)$ & & \\
\hline A little serious & $4(10 \%)$ & & \\
\hline
\end{tabular}

$\mathrm{p}<0.05$ : statistical significance.

therefore, these children experienced more emotional and behavioral problems.

Our study supports previous studies that reported emotional and behavioral problems and psychiatric problems in children of mothers with BC.[18,21,27,30, 37] Many psychological problems, such as externalizing behaviors (aggressiveness and defiance), and emotional problems (sadness, emotional lability, internal- izing problems, and somatic complaints) can be seen in these children.[21,30,38-40] A study in 2018 that reviewed the literature with regard to the psychological, social, and behavioral effects of parental cancer on 10-24-year-old children reported that most of these children were significantly affected by parental cancer.[41] In contrast to these studies, a study showed that patients followed for 1 year with a diagnosis of 
Table 2 SDQ subscale scores of the study and control groups

\begin{tabular}{lccc} 
& $\begin{array}{c}\text { Study } \\
\text { group } \\
\text { (Mean } \pm \text { SD) }\end{array}$ & $\begin{array}{c}\text { Controls } \\
\text { group } \\
\text { (Mean } \pm \text { SD) }\end{array}$ & p \\
\hline Emotional problems & $4.52 \pm 2.03$ & $4.27 \pm 1.83$ & 0.566 \\
Conduct & $2.42 \pm 1.85^{*}$ & $1.07 \pm 1.22$ & $<0.001$ \\
Attention deficit and hyperactivity & $4.02 \pm 2.28^{*}$ & $2.32 \pm 2.05$ & 0.001 \\
Peer & $3.77 \pm 1.83$ & $3.57 \pm 1.00$ & 0.548 \\
Prosocial & $8.17 \pm 1.99$ & $8.47 \pm 1.79$ & 0.482 \\
Total & $14.70 \pm 5.54^{*}$ & $11.25 \pm 3.83$ & 0.002 \\
\hline
\end{tabular}

SDQ: Strengths and Difficulties Questionnaire.

$\mathrm{p}<0.05$ : statistical significance.

*Higher than those of controls.

Table 3 SDQ subscale scores of the study group according to gender

\begin{tabular}{|c|c|c|c|}
\hline & $\begin{array}{c}\text { Female } \\
(\text { Mean } \pm \text { SD }) / \mathrm{n}(\%)\end{array}$ & $\begin{array}{c}\text { Male } \\
(\text { Mean } \pm \text { SD }) / \mathrm{n}(\%)\end{array}$ & $\mathbf{p}$ \\
\hline Emotional problems & $5.08 \pm 1.84^{*}$ & $3.60 \pm 2.06$ & 0.024 \\
\hline Conduct & $2.68 \pm 1.81$ & $2.00 \pm 1.88$ & 0.266 \\
\hline Attention deficit and hyperactivity & $4.12 \pm 2.02$ & $3.86 \pm 2.72$ & 0.739 \\
\hline Peer & $4.28 \pm 1.67^{*}$ & $2.93 \pm 1.83$ & 0.022 \\
\hline Prosocial & $8.20 \pm 1.68$ & $8.13 \pm 2.50$ & 0.920 \\
\hline Total & $16.16 \pm 4.63^{*}$ & $12.26 \pm 6.22$ & 0.030 \\
\hline Age range & & & 0.013 \\
\hline 6-11 age & $4(16 \%)$ & $8(53.3 \%)$ & \\
\hline $12-17$ age & $21(84 \%)$ & $7(46.7 \%)$ & \\
\hline Family roles & & & 0.220 \\
\hline Changed (caregiver and mother) & $15(60 \%)$ & $6(40 \%)$ & \\
\hline Unchanged & $10(40 \%)$ & $9(60 \%)$ & \\
\hline \multicolumn{4}{|l|}{ New responsibilities } \\
\hline Being the mother's caregiver & $5(20 \%)$ & $4(26.7 \%)$ & \\
\hline Undertaking responsibilities of siblings & $10(40 \%)$ & $2(13.3 \%)$ & \\
\hline Do housework & $10(40 \%)$ & $3(20 \%)$ & \\
\hline Other & $5(20 \%)$ & $3(20 \%)$ & \\
\hline \multicolumn{4}{|l|}{ Experienced difficulties } \\
\hline Limitation of daily activities & $11(44 \%)$ & $3(20 \%)$ & \\
\hline Decrease in social activity with peer grups & $5(20 \%)$ & $3(20 \%)$ & \\
\hline Decrease in lesson work & $9(36 \%)$ & $5(33.3 \%)$ & \\
\hline Other & $5(20 \%)$ & $4(26.7 \%)$ & \\
\hline Fears of becoming ill & & & 0.033 \\
\hline Yes & $17(68 \%)$ & $5(33.3 \%)$ & \\
\hline No & $8(32 \%)$ & $10(66.7 \%)$ & \\
\hline Reaction to the disease & & & 0.061 \\
\hline Yes (sorry, cry, anxiety ie) & $25(100 \%)$ & $0(0 \%)$ & \\
\hline No & $2(13.3 \%)$ & $13(86.7 \%)$ & \\
\hline
\end{tabular}

SDQ: Strengths and Difficulties Questionnaire.

$\mathrm{p}<0.05$ : statistical significance.

*Higher than those of controls.

BC had better function than a group not affected by cancer.[29] In another study, 6-12-year-old children of mothers with non-metastatic BC had lower self- esteem than children of mothers with benign $\mathrm{BC}$ but had better mean behavioral adjustment than those of the non-cancer group.[42] Moreover, a study evalu- 
Table 4 SDQ subscale scores of the study group according to age range

\begin{tabular}{|c|c|c|c|}
\hline & $\begin{array}{c}\text { 6-11 age } \\
(\text { Mean } \pm \text { SD }) / n(\%)\end{array}$ & $\begin{array}{c}\text { 12-17 age } \\
(\text { Mean } \pm S D) / n(\%)\end{array}$ & $\mathbf{p}$ \\
\hline Emotional problems & $3.91 \pm 1.78$ & $4.78 \pm 2.11$ & 0.221 \\
\hline Conduct & $1.75 \pm 1.65$ & $2.71 \pm 1.88$ & 0.133 \\
\hline Attention deficit and hyperactivity & $3.33 \pm 2.34$ & $4.32 \pm 2.22$ & 0.214 \\
\hline Peer & $3.33 \pm 1.37$ & $3.96 \pm 1.99$ & 0.325 \\
\hline Prosocial & $8.50 \pm 2.19$ & $8.03 \pm 1.93$ & 0.508 \\
\hline Total & $12.25 \pm 4.67$ & $15.75 \pm 5.63$ & 0.067 \\
\hline Gender (female/male) & $4 / 8$ & $21 / 7$ & 0.013 \\
\hline Awareness of the diagnosis ( $\mathrm{n} / \%)$ & & & 0.037 \\
\hline Yes & $6(50 \%)$ & $23(82.1 \%)$ & \\
\hline No & $6(50 \%)$ & $5(17.9 \%)$ & \\
\hline Reaction to the disease & & & 0.027 \\
\hline Yes (sorry, cry, anxiety) & $10(83.3 \%)$ & $28(100 \%)$ & \\
\hline No & $2(16.7 \%)$ & $0(0 \%)$ & \\
\hline Family roles & & & 0.023 \\
\hline Changed (caregiver and mother) & $3(25 \%)$ & $18(64.3 \%)$ & \\
\hline Unchanged & $9(75 \%)$ & $10(35.7 \%)$ & \\
\hline \multicolumn{4}{|l|}{ New responsibilities } \\
\hline Being the mother's caregiver & $0(0 \%)$ & $9(32.1 \%)$ & \\
\hline Undertaking responsibilities of siblings & $1(8.3 \%)$ & $10(35.7 \%)$ & \\
\hline Do housework & $2(16.7 \%)$ & $11(39.3 \%)$ & \\
\hline Other & $2(16.7 \%)$ & $6(21.4 \%)$ & \\
\hline \multicolumn{4}{|l|}{ Experienced difficulties } \\
\hline Limitation of daily activities & $3(25 \%)$ & $11(39.3 \%)$ & \\
\hline Decrease in social activity with peer grups & $2(16.7 \%)$ & $6(21.4 \%)$ & \\
\hline Decrease in lesson work & $3(25 \%)$ & $11(39.3 \%)$ & \\
\hline Other & $4(33.3 \%)$ & $5(17.8 \%)$ & \\
\hline
\end{tabular}

SDQ: Strengths and Difficulties Questionnaire. $\mathrm{p}<0.05$ : statistical significance.

ated 6-17-year-old children of patients with BC using the $\mathrm{CBCL}$ and reported no difference in internalizing and externalizing subscale scores or total score. However, self-reports by girls yielded higher $\mathrm{t}$-scores than questionnaires filled out by the parents. A significant minority of school-age children of mothers with earlystage BC had emotional and behavioral problems.[13]

In our study, it was determined that girls had statistically significantly more problems in emotional, peer relationship, and total difficulty areas than boys. Similar to our study, previous studies have shown that internalizing disorders, such as depression and anxiety, were more prevalent in girls, whereas hostility and irritability were more prevalent in boys. $[19,40]$ Many studies have demonstrated that especially adolescent girls had a high risk for internalizing problems if their mother had a hereditary cancer disease, such as BC, because they worried about the long-term effects of the disease and about the hereditary risk of their becom- ing ill. [21,40] We also found that girls had more fear of getting the illness than boys. Less frequent emotional problems in males in our study may be due to less common expression of emotions in males.

In our study, there was a significant relationship between age and total difficulty score in children of mothers with BC. As age increased, the total difficulty score of children also increased. However, in our study, prosocial behavior subscale score was lower, and emotional problems, peer problems, attention deficit and hyperactivity, and total difficulty scores were higher in 12-17-year-old adolescents than in 6-11-year-old children although the differences were not statistically significant. This may be due to small sample size. Nevertheless, these results show that every age group is affected by mother's BC.

A study result demonstrated that primary school and adolescent children had similar levels of emotional and behavioral problems within 4 months after the parent's cancer diagnosis to children of the norm group 
and children of parents diagnosed 1 to 5 years ago (retrospective group).[19] However, in some studies, it was reported that a high percentage of children had higher clinical scores for emotional problems during the first months after their parents were diagnosed.[43,44] In our study, children whose mothers were diagnosed in the last year had higher scores in emotional problems, conduct problems, attention deficit and hyperactivity, and total difficulty and lower scores in peer problems and prosocial behaviors than children whose mothers were diagnosed 1-5 years ago although the difference was not statistically significant. This may be related to the small number of cases.

Previous studies demonstrated that alterations in social roles occurred, and that new responsibilities, such as assuming parental role, limitation of daily activities, undertaking responsibilities of siblings, and having to do housework, developed in caregiving family members of patients with cancer. These new responsibilities bring additional emotional and physical burdens on children and cause psychological distress. Children and adolescents of patients with BC had various problems, such as changes in family responsibilities and some life challenges.[16,30,31] In our study, lifestyle changes and responsibilities were more common especially in the adolescent group. This may be due to the expectation of parents and caregivers that the adolescent should take more responsibility and provide more support to the family as he/she gets older.

The primary limitation of the present study was its cross-sectional design. Our study was conducted with a small sample size. For this reason, it cannot be generalized to children of all patients with BC. Another limitation was that the psychiatric examination of the cases was not performed, and they were not assessed by a semistructured psychiatric interview, such as the Schedule for Affective Disorders and Schizophrenia for School-Aged Children, Present and Lifetime Version. Another limitation was the use of measurement tools based on self-reports of the families for the groups. It is also a limitation that a scale that measures the self-esteem of adolescent patients was not used. However, to the best of our knowledge, this is the first study to identify emotional and behavioral problems and difficulties in under 18-year-old children of mothers with BC in Turkey that may form the basis for future prospective, large-scale studies.

\section{Conclusion}

The results of the present study showed that the emotional and behavioral problems of children and ado- lescents of mothers with $\mathrm{BC}$ were higher than those of healthy children with healthy parents, and that maternal illness caused distress for children in many areas of their lives. There was a positive relationship between increasing age and total difficulty, and more emotional and behavioral problems were observed in girls. The results of this contemporary study may increase the awareness of health care providers that some children may have difficulties in adjusting to their parents' illness. Health care providers can help parents to support their children in the early stages of cancer and to be particularly sensitive to children at risk.

Acknowledgment: The authors wish to thank the patients and families who participated in this study.

Peer-review: Externally peer-reviewed.

Conflict of Interest: None declared.

Ethics Committee Approval: The study was approved by the scientific research Ethical Committee of Sütçü İmam University, Medical Faculty, Kahramanmaraş.

Financial Support: None declared.

Authorship contributions: Concept - H.A., N.K., A.A., E.M.K.; Design - H.A., N.K., A.A., E.M.K.; Supervision - H.A., N.K., A.A., E.M.K.; Materials - H.A., N.K., A.A., E.M.K.; Data collection \&/or processing - H.A., N.K., A.A., E.M.K.; Analysis and/or interpretation - H.A., N.K.; Literature search - H.A., N.K., A.A., E.M.K.; Writing - H.A., N.K.; Critical review - H.A., N.K., A.A., E.M.K.

\section{References}

1. Torre LA, Bray F, Siegel RL, Ferlay J, Lortet-Tieulent J, Jemal A. Global cancer statistics, 2012. CA Cancer J Clin 2015;65(2):87-108.

2. Siegel RL, Miller KD, Jemal A. Cancer statistics, 2018. CA Cancer J Clin 2018;68(1):7-30.

3. Anders CK, Johnson R, Litton J, Phillips M, Bleyer A. Breast cancer before age 40 years. Semin Oncol 2009;36(3):237-49.

4. Kitrungroter L, Cohen MZ. Quality of life of family caregivers of patients with cancer: a literature review. Oncol Nurs Forum 2006;33(3):625-32.

5. Mystakidou K, Tsilika E, Parpa E, Galanos A, Vlahos L. Caregivers of advanced cancer patients: feelings of hopelessness and depression. Cancer Nurs 2007;30(5):412-8.

6. Zahlis EH, Shands ME. Breast cancer: Demands of the illness on the patient's partner. J Psychosoc Oncol 1991;9(1):75-93. 
7. Moore CW, Rauch PK, Baer L, Pirl WF, Muriel AC. Parenting changes in adults with cancer. Cancer 2015;121(19):3551-7.

8. Götze H, Friedrich M, Brähler E, Romer G, Mehnert A, Ernst J. Psychological distress of cancer patients with children under 18 years and their partners-a longitudinal study of family relationships using dyadic data analysis. Support Care Cancer 2017;25(1):255-64.

9. Krauss O, Ernst J, Kuchenbecker D, Hinz A, Schwarz R. Predictors of mental disorders in patients with malignant diseases: empirical results. [Article in German]. Psychother Psychosom Med Psychol 2007;57(7):27380.

10. Helseth S, Ulfsaet N. Parenting experiences during cancer. J Adv Nurs 2005;52(1):38-46.

11. Lewis FM, Hammond MA. The father's, mother's, and adolescent's functioning with breast cancer. Family Relations 1996;45(4):456-65.

12. Kissane DW, Bloch S, Dowe DL, Snyder RD, Onghena P, McKenzie DP, et al. The Melbourne Family Grief Study, I: Perceptions of family functioning in bereavement. Am J Psychiatry 1996;153(5):650-8.

13. Watson M, St James-Roberts I, Ashley S, Tilney C, Brougham B, Edwards L, et al. Factors associated with emotional and behavioural problems among school age children of breast cancer patients. Br J Cancer 2006;94(1):43-50.

14. Connell S, Patterson C, Newman B. Issues and concerns of young Australian women with breast cancer. Support Care Cancer 2006;14(5):419-26.

15. Northouse LL, Cracchiolo-Caraway A, Appel CP. Psychologic consequences of breast cancer on partner and family. Semin Oncol Nurs 1991;7(3):216-23.

16. Buchbinder M, Longhofer J, McCue K. Family routines and rituals when a parent has cancer. Fam Syst Health 2009;27(3):213-27.

17. Huizinga GA, Visser A, van der Graaf WT, Hoekstra HJ, Klip EC, Pras E, et al. Stress response symptoms in adolescent and young adult children of parents diagnosed with cancer. Eur J Cancer 2005;41(2):288-95.

18. Thastum M, Watson M, Kienbacher C, Piha J, Steck B, Zachariae R, et al. Prevalence and predictors of emotional and behavioural functioning of children where a parent has cancer: a multinational study. Cancer 2009;115(17):4030-9.

19. Visser A, Huizinga GA, Hoekstra HJ, van der Graaf WT, Gazendam-Donofrio SM, Hoekstra-Weebers JE. Emotional and behavioral problems in children of parents recently diagnosed with cancer: a longitudinal study. Acta Oncol 2007;46(1):67-76.

20. Visser A, Huizinga GA, van der Graaf WT, Hoekstra HJ, Hoekstra-Weebers JE. The impact of parental cancer on children and the family: a review of the literature. Cancer Treat Rev 2004;30(8):683-94.
21. Compas BE, Worsham NL, Epping-Jordan JE, Grant KE, Mireault G, Howell DC, et al. When mom or dad has cancer: markers of psychological distress in cancer patients, spouses, and children. Health Psychol 1994;13(6):507-15.

22. Visser A, Huizinga GA, Hoekstra HJ, van der Graaf WT, Hoekstra-Weebers JE. Parental cancer: characteristics of parents as predictors for child functioning. Cancer 2006;106(5):1178-87.

23. Huizinga GA, Visser A, Zelders-Steyn YE, Teule JA, Reijneveld SA, Roodbol PF. Psychological impact of having a parent with cancer. Eur J Cancer 2011;47 Suppl 3:S239-46.

24. Gazendam-Donofrio SM, Hoekstra HJ, van der Graaf WT, Pras E, Visser A, Huizinga GA, et al. Quality of life of parents with children living at home: when one parent has cancer. Support Care Cancer 2008;16(2):133-41.

25. Howes MJ, Hoke L, Winterbottom M, Delafield D. Psychoso- cial effects of breast cancer on the patient's children. J Psychosoc Oncol 1994;12:1-21.

26. Heiney SP, Bryant LH, Walker S, Parrish RS, Provenzano FJ, Kelly KE. Impact of parental anxiety on child emotional adjustment when a parent has cancer. Oncol Nurs Forum 1997;24(4):655-61.

27. Visser A, Huizinga GA, Hoekstra HJ, van der Graaf WT, Klip EC, Pras E, et al. Emotional and behavioural functioning of children of a parent diagnosed with cancer: a cross-informant perspective. Psychooncology 2005;14(9):746-58.

28. Huizinga GA, van der Graaf WT, Visser A, Dijkstra JS, Hoekstra-Weebers JE. Psychosocial consequences for children of a parent with cancer: a pilot study. Cancer Nurs 2003;26(3):195-202.

29. Hoke LA. Psychosocial adjustment in children of mothers with breast cancer. Psychooncology 2001;10(5):361-9.

30. Grabiak BR, Bender CM, Puskar KR. The impact of parental cancer on the adolescent: an analysis of the literature. Psychooncology 2007;16(2):127-37.

31. Shah BK, Armaly J, Swieter E. Impact of Parental Cancer on Children. Anticancer Res 2017;37(8):4025-8.

32. Glasdam S, Jensen AB, Madsen EL, Rose C. Anxiety and depression in cancer patients' spouses. Psychooncology 1996;5(1):23-9.

33. Ollonen P, Lehtonen J, Eskelinen M. Anxiety, depression, and the history of psychiatric symptoms in patients with breast disease: a prospective casecontrol study in Kuopio, Finland. Anticancer Res 2005;25(3c):2527-33.

34. Çivi S, Kutlu R, Çelik HH. Kanserli hasta yakınlarında depresyon ve yaşam kalitesini etkileyen faktörler. Gulhane Tip Derg 2011;53(4):248-53.

35. Edwards B, Clarke V. The psychological impact of a cancer diagnosis on families: the influence of 
family functioning and patients' illness characteristics on depression and anxiety. Psychooncology 2004;13(8):562-76.

36. Güvenir T, Özbek A, Baykara B, Arkar H, Şentürk $\mathrm{B}$, İncekaş S. Psychometric properties of the turkish version of the strengths and difficulties questionnaire (SDQ). Çocuk ve Gençlik Ruh Sağliği Dergisi 2008; 15:65-74.

37. Osborn T. The psychosocial impact of parental cancer on children and adolescents: a systematic review. Psychooncology 2007;16(2):101-26.

38. Al-Zaben F, Al-Amoudi SM1, El-deek BS, Koenig HG. Impact of maternal breast cancer on school-aged children in Saudi Arabia. BMC Res Notes 2014;7:261.

39. Birenbaum LK, Yancey DZ, Phillips DS, Chand N, Huster G. School-age children's and adolescents' adjustment when a parent has cancer. Oncol Nurs Forum 1999;26(10):1639-45.
40. Morris JN, Martini A, Preen D. The well-being of children impacted by a parent with cancer: an integrative review. Support Care Cancer 2016;24(7):3235-51.

41. Morris J, Turnbull D, Preen D, Zajac I, Martini A. The psychological, social, and behavioural impact of a parent's cancer on adolescent and young adult offspring aged 10-24 at time of diagnosis: A systematic review. J Adolesc 2018;65:61-71.

42. Armsden GC, Lewis FM. Behavioral adjustment and self-esteem of school-age children of women with breast cancer. Oncol Nurs Forum 1994;21(1):39-45.

43. Nelson E, While D. Children's adjustment during the first year of a parent's cancer diagnosis. J Psychosoc Oncol 2002;20(1):15-36.

44. Mireault GC, Compas BE. A prospective study of coping and adjustment before and after a parent's death from cancer. J Psychosoc Oncol 1997;14(4):118. 